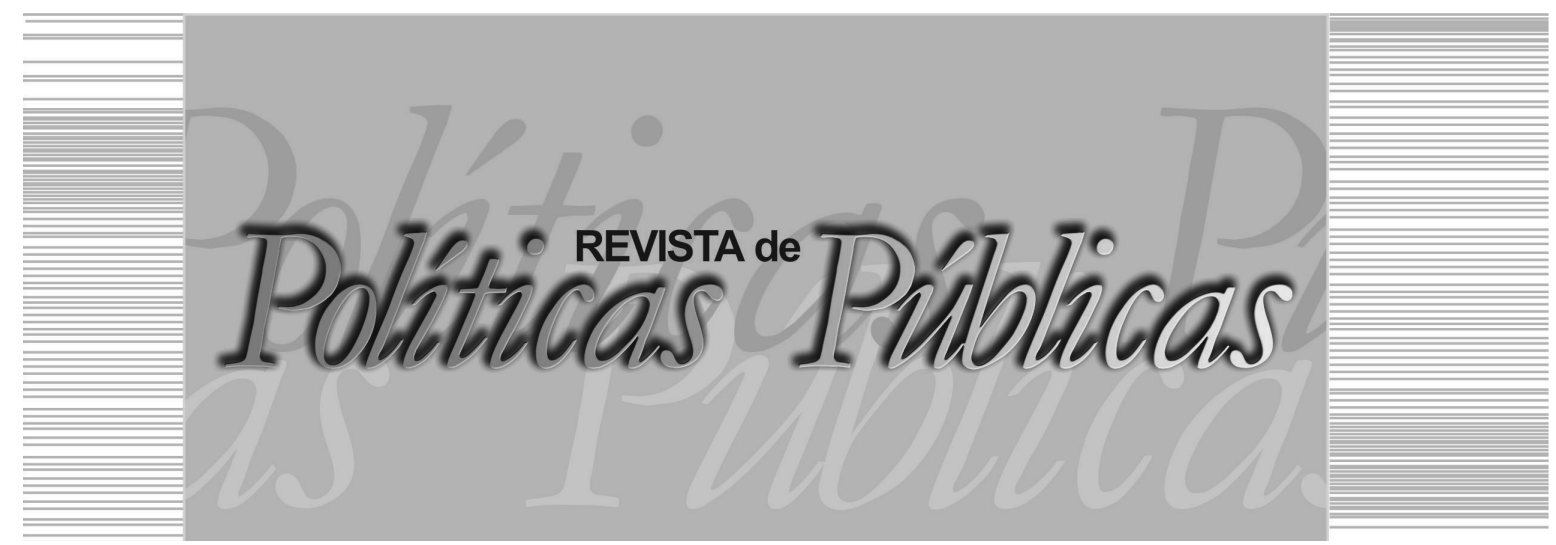

\title{
AVALIAÇÃO DO PROGRAMA UM MILHÃO DE CISTERNAS RURAIS (PTMC): eficácia, eficiência e efetividade nos territórios do Rio Grande do Norte (2003/2015)
}

Hugo Azevedo Rangel de Morais ${ }^{I}$ Universidade Federal do Sul e Sudeste do Pará (UNIFESSPA)

Juarez Azevedo de Paiva ${ }^{2}$ Universidade Federal do Rio Grande do Norte (UFRN)

Washington José de Sousa ${ }^{3}$ Universidade Federal do Rio Grande do Norte (UFRN)

\section{Resumo}

A escassez de água é problema recorrente no semiárido brasileiro, mais precisamente no Nordeste. As primeiras iniciativas, de atenção à estiagem, surgiram mediante ações públicas sociais de "salvação", de mitigação das consequências da seca. Perdurou, até os anos 1980, tal perspectiva de "combate à seca". Desde então, com a redemocratização do País e a reforma do Estado, novas alternati-

Contador, Mestre em Administração pela Universidade Federal do Rio Grande do Norte (UFRN), Professor Titular do Departamento de Ciências Contábeis da Universidade Federal do Sul e Sudeste do Pará (UNIFESSPA)/Campus Rondon do Pará. E-mail: hugoazevedomorais@gmail.com

2 Administrador, Doutorando do Programa de Pós-Graduação em Administração da UFRN, Professor Colaborador do Departamento de Ciências Administrativas e do Curso de Especialização em Economia Solidária e Desenvolvimento Territorial da UFRN. E-mail: juarez_paiva@yahoo.com.br / Universidade Federal do Sul e Sudeste do Pará UNIFESSPA: Campus Rondon do Pará - Folha 31, Quadra 07, Lote Especial, s/n, Nova Marabá, Marabá - PA. CEP 68507-590

3 Administrador, Doutor em Educação pela Universidade Federal do Ceará (UFC), Professor Titular do Departamento de Ciências Administrativas da UFRN. E-mail: wsufrn@gmail. com / Universidade Federal do Rio Grande do Norte - UFRN: Campus Universitário Lagoa Nova, Natal - RN. CEP 59078-970 
vas para o desenvolvimento do semiárido brasileiro começaram a surgir a partir de organizações da sociedade civil, que passaram a realizar projetos com base no ideal de que é possível e necessário conviver com o semiárido. Este estudo situa-se, pois, nesse novo momento de ações públicas destinadas ao semiárido, assumindo o intento de sistematizar resultados do Programa Um Milhão de Cisternas Rurais (P1MC) à luz dos indicadores eficácia, eficiência e efetividade. A pesquisa foi do tipo descritiva, o universo compreendeu os 10 territórios do Rio Grande do Norte, a abordagem foi quantitativa e qualitativa. Para o tratamento dos dados quantitativos, utilizou-se análise envoltória de dados (DEA), através do software Siadv e, na etapa qualitativa, análise de conteúdo com auxilio do software NVivo 11. Os resultados apontaram que, em termos de eficácia, representada pelas metas físicas preestabelecidas, o Programa ficou aquém do esperado. $\mathrm{O}$ estudo conclui que, em termos de eficiência, destacam-se os territórios Sertão do Apodi, Açu-Mossoró e Mato Grande. No tocante à efetividade, os pressupostos analisados do Programa são amplamente atendidos no conteúdo e na forma.

Palavras-chave: Ação pública não governamental, efetividade, eficiência, eficácia, convivência com o semiárido.

EVALUATION OF THE PROGRAM A MILLION RURAL

CISTERNS (P1MC): effectiveness, efficiency and effectiveness in the territories of Rio Grande do Norte (2003/2015)

\begin{abstract}
Water scarcity is a recurrent problem in the Brazilian semi-arid region, more precisely in the Northeast. The first initiatives, focusing on the drought, came about through public social actions of "salvation", mitigating the consequences of the drought. Until the 1980s, this perspective of "combating drought" remained. Since then, with the country's redemocratization and state reform, new alternatives for the development of the Brazilian semi-arid began to emerge from civil society organizations that started to carry out projects based on the ideal that it is possible and necessary to live with Or semiarid. This study is therefore in this new moment of public actions aimed at the semi-arid region, assuming the attempt to systematize the results of the One Million Rural Cisterns Program (P1MC) in the light of efficiency, effectiveness and effectiveness indicators. The research was of the descriptive type, the universe comprised the 10 territories of Rio Grande do Norte, the approach was quantitative and qualitative. For the treatment of quantitative data, we used data envelopment analysis (DEA) using Siadv software and, in the qualitative step, content analysis using NVivo 11 software. The results showed that, in terms of efficacy, Pre-established physical targets, the Program has fallen short of expectations. The study concludes that in terms of efficiency, the territories of Sertão do
\end{abstract}


AVALIACCÃO DO PROGRAMA UM MILHÃO DE CISTERNAS RURAIS (PIMC):

eficácia, eficiência e efetividade nos territórios do Rio Grande do Norte (2003-2015)

Apodi, Açu-Mossoró and Mato Grande stand out. With regard to effectiveness, the analyzed assumptions of the Program are largely met in content and form. Key words: Non-governmental public action, effectiveness, efficiency, efficacy, coexistence with the semi-arid.

\section{INTRODUÇÃO}

O semiárido brasileiro representa percentual relevante da região Nordeste e concentra os piores indicadores sociais do País em termos de educação, saúde, mortalidade infantil e analfabetismo, comprometendo ainda mais o ambiente socioeconômico e político, marcado pela concentração de poder e renda, sobretudo na zona rural. (LIRA et al., 2011). Esse panorama prejudica consubstancialmente as condições que norteiam a qualidade de vida da população. Diante de tal entendimento, ao longo dos anos advieram várias ações com o objetivo de minimizar as condições indesejáveis do semiárido, de modo a tornar possível a sobrevivência na região por meio do desenvolvimento de tecnologias apropriadas.

Para Demo (2006), não é a seca a responsável pela pobreza, mas a indústria da seca. A ausência de chuva é condição natural, não representando problema social. A escassez de água, por sua vez, é problema recorrente. Há anos, aparecem tentativas, por meio de ações públicas, para correção das consequências da seca. Entretanto, o fracasso relativo é notável frente a situações de pobreza e exclusão que se perpetuam no semiárido do Nordeste. Passador e Passador (2010) alegam que a atuação interventora do Estado no Nordeste foi constantemente representada pela centralização e fragmentação de ações limitadas à criação de órgãos nacionais para combate à seca, os quais se transformavam em objeto de disputas políticas entre diversos segmentos da elite rural. Dentre as principais ações, esteve sempre, a construção de açudes, com o intuito de assegurar água para produção agropecuária.

Ocorreu, então, uma transição paradigmática, e o modelo de combate à seca cedeu lugar à convivência com o semiárido, resultado de vivências e da produção de conhecimentos em torno de novas tecnologias de captação e armazenamento de água de chuva, manejo sustentado da caatinga, tecnologias alternativas de produção, soberania alimentar, educação contextualizada, entre outras. Imprescindível tem sido a busca por viver o semiárido, no semiárido, com o semiárido. 
Frente a tais argumentos, este artigo soma-se a outros estudos e entendimentos relativos ao semiárido brasileiro, com foco no gerenciamento de recursos hídricos, para revelar resultados alcançados pela Articulação Semiárido Brasileiro (ASA) por meio do Programa de Formação e Mobilização Social para a Convivência com o Semiárido: Um Milhão de Cisternas Rurais (P1MC). O P1MC tem como objetivo geral contribuir, mediante um processo educativo, para a transformação social, visando à preservação, ao acesso, ao gerenciamento e à valorização da água como um direito essencial da vida e da cidadania, ampliando a compreensão e a prática da convivência sustentável e solidária com o ecossistema do semiárido, legitimando a mudança de paradigma, em que as "[...] políticas públicas de combate às secas" passam a ser "[...] políticas de convivência com o semiárido" (ARTICULACCÃO SEMIÁRIDO BRASILEIRO, 2016). O referido Programa dispõe de componentes como Mobilização das Famílias, Cursos de Gerenciamento da Água, Encontros Microrregionais, Capacitações e a Construção das Cisternas com capacidade para 16 mil litros. O Programa, iniciado em 2003 como politica pública, tem recorte regional, destinado ao atendimento de uma das principais necessidades da população da zona rural: oferecer água para o consumo da família durante o período das estiagens no semiárido. (LOPES; LIMA, 2009).

Arretche (2001, p. 31) relata que "[...] somente a avaliação de programas efetivamente implementados poderá estabelecer uma relação causal entre determinada modalidade de política pública e o sucesso e o fracasso na realização de seus propósitos". Nesse sentido, a avaliação consiste na adoção de métodos e técnicas de pesquisa que permitam estabelecer uma relação de causalidade entre um programa x e um resultado y. (FIGUEIREDO; FIGUEIREDO, 1986). Complementarmente, Antico e Jannuzzi (2006 apud SANO; MONTENEGRO FILHO, 2013, p. 37), defendem que "[...] a avaliação de um programa público requer indicadores que possam dimensionar o grau de cumprimento dos objetivos dos mesmos (eficácia), o nível de utilização de recursos frente aos custos em disponibilizá-los (eficiência) e a efetividade social". Partindo dessas premissas, são aqui explorados indicadores de eficácia, eficiência e efetividade a partir da seguinte questão central: que resultados têm o P1MC, entre 2003 e 2015, em termos de eficácia, eficiência e efetividade nos territórios potiguares? 
AVALIACCÃO DO PROGRAMA UM MILHÃO DE CISTERNAS RURAIS (PIMC):

eficácia, eficiência e efetividade nos territórios do Rio Grande do Norte (2003-2015)

A partir do problema acima enunciado, esta pesquisa assume o objetivo de descrever resultados do Programa Um Milhão de Cisternas, nos territórios do Rio Grande do Norte, tomando como base indicadores quantitativos de eficiência e eficácia e, atributos qualitativos de efetividade, interpretados a partir do atendimento aos pressupostos analisados, declarados pela ASA.

\section{DESENVOLVIMENTO}

A política pública agrega conteúdo simbólico de decisões políticas e a consequente construção de suas decisões em instrumentos concretos. É comum na literatura encontrar termos pertinentes e correlacionados, tais como: ciclo de políticas públicas, processo de construção da política pública, atores políticos, dinâmica da política pública. (HOWLETT; RAMESH; PERL, 2013). Para Matias-Pereira (2012), a política pública compreende um elenco de ações e procedimentos que visam à resolução pacífica de conflitos em torno da alocação de bens e recursos públicos, sendo os indivíduos integrantes desse processo comumente nominados de atores. Tal termo, na língua portuguesa, pode assumir duas conotações que a língua inglesa consegue diferenciar usando os termos: (a) politics, designado ao exercício humano do poder; e (b) policy, que é o processo de orientação para decisão. (SECCHI, 2014).

Políticas públicas são ações intencionais dos governos, advindas do resultado de um processo técnico-político, construído com o escopo de compatibilizar objetivos e meios entre atores sociais. (HOWLETT; RAMESH; PERL, 2013). Do ponto de vista de Secchi (2014), a área das políticas públicas tem a dimensão técnico-administrativa, isto é, busca eficiência e resultados práticos. No entanto, possui uma dimensão política, que está relacionada ao processo decisório, competindo ao Estado fazer escolhas, na área social, sobre onde, por que e quando atuar. Smith (1973) utiliza outra nomenclatura, fazendo uso do termo políticas governamentais para indicar aquela política que objetiva trazer e provocar mudanças na sociedade. Souza (2006), por sua vez, argumenta que a política pública trata da transformação de propósitos e intenções em ações que objetivam produzir resultados efetivos no mundo real.

Na qualidade de tema atinente a esta pesquisa, no processo, a avaliação constitui-se na atividade final. Avaliar uma política é um dos estágios do ciclo das políticas públicas, integra-se ao ciclo como 
atividade frequente que acompanha todas as fases da política pública, desde a identificação do problema até a análise das mudanças sociais oriundas da intervenção pública. É um instrumento de gestão quando se pretende legitimar decisões a respeito de continuidade, aperfeiçoamentos necessários, responsabilização dos agentes; representa accountability quando informa, aos usuários, beneficiários e sociedade em geral desempenhos e efeitos. A esse respeito, Cavalcanti (2006, p. 6) afirma que:

A avaliação de políticas públicas não é simplesmente um instrumento de aperfeiçoamento ou de redirecionamento dos programas empreendidos pelo governo, mas, e especialmente, uma ferramenta capaz de prestar contas à sociedade das ações governamentais. Nessa perspectiva envolve o diálogo público - controle social - na sua dinâmica, pois a qualidade dos programas só aumenta quando a participação dos usuários é intensificada e efetivamente acontece.

Corroborando Cavalcanti (2006), Frey (2001, p. 229) afirma que "[...] a fase da avaliação é imprescindível para o desenvolvimento e a adaptação contínua das formas e instrumentos de ação pública". Sendo assim, representa um aprendizado sobre a própria prática, resultando na tentativa da busca pela qualidade da política pública. Ainda que a avaliação seja conceituada estágio isolado no ciclo da política, ela tem sido utilizada nos modelos que aderem a tal perspectiva, como uma ferramenta para subsidiar a tomada de decisão nas variadas fases que ocorrem ao longo do ciclo.

Faria (2005) apresenta quatro finalidades e tipos de avaliação: (a) o uso instrumental, que para a tomada de decisão depende não apenas da qualidade da avaliação, mas, também, da adequada divulgação de seus resultados, de sua inteligibilidade e da factibilidade das recomendações eventualmente propostas; (b) o uso conceitual, cuja aprendizagem torna-se maximizada quando os técnicos participam mais ativamente do processo de avaliação; (c) o uso da avaliação como instrumento de persuasão, que se dá quando ela é utilizada para mobilizar o apoio para a posição que os tomadores de decisão já têm sobre as mudanças necessárias na política ou programa; (d) o uso da avaliação como instrumento de esclarecimentos, via acúmulo de conhecimento oriundo de diversas avaliações, impacto sobre as redes de profissionais, sobre os formadores de opinião.

Valorizando critérios, Arretche (1999) defende que qualquer forma de avaliação envolve necessariamente um julgamento, enfatizando que se trata primordialmente de atribuir um valor, uma medida 
AVALIACCÃO DO PROGRAMA UM MILHÃO DE CISTERNAS RURAIS (PIMC):

eficácia, eficiência e efetividade nos territórios do Rio Grande do Norte (2003-2015)

de aprovação ou desaprovação a uma política ou programa público particular, de analisá-la a partir de uma certa concepção de justiça. Em busca da distinção entre as opções pessoais e os resultados encontrados, Jannuzzi (2005) enfatiza a importância da utilização do conjunto de indicadores das diversas naturezas e propriedades, bem como o manuseio adequado de banco de dados, em função das necessidades intrínsecas das atividades envolvidas. Contudo, para boa elaboração do diagnóstico da política ou programa social, são necessários indicadores de boa confiabilidade, validade e desagregabilidade, em cada etapa, como exemplificado no Quadro 1.

Quadro 1 - Indicadores em cada etapa do ciclo de programas sociais

\begin{tabular}{|l|l|l|}
\hline \multicolumn{1}{|c|}{ ETAPA } & \multicolumn{1}{|c|}{ TIPOS E PROPRIEDADES } & \multicolumn{1}{c|}{$\begin{array}{c}\text { FONTE DE DADOS } \\
\text { PREDOMINANTE }\end{array}$} \\
\hline $\begin{array}{l}\text { Elaboração do Diagnóstico } \\
\text { Indicadores que permitam } \\
\text { "retratar" a realidade social. }\end{array}$ & $\begin{array}{l}\text { Amplo escopo temático; } \\
\text { ampla desagregabilidade } \\
\text { geográfica e populacional; } \\
\text { validade de construto; boa } \\
\text { confiabilidade. }\end{array}$ & $\begin{array}{l}\text { Censos demográficos; } \\
\text { pesquisas amostrais. }\end{array}$ \\
\hline $\begin{array}{l}\text { Formulação de Programas } \\
\text { É seleção de alternativas/ } \\
\text { indicadores que orientem } \\
\text { objetivamente a tomada de } \\
\text { decisão, }\end{array}$ & $\begin{array}{l}\text { Indicadores sintéticos; } \\
\text { indicadores multicriteriais; } \\
\text { tipologias de situações } \\
\text { sociais. }\end{array}$ & $\begin{array}{l}\text { Censos demográficos; } \\
\text { pesquisas amostrais. }\end{array}$ \\
\hline $\begin{array}{l}\text { Implementação/Execução } \\
\text { Indicadores que permitam } \\
\text { "filmar" o processo de } \\
\text { implementação dos } \\
\text { programas formulados e a } \\
\text { eficiência. }\end{array}$ & $\begin{array}{l}\text { Esforço (insumo/processos); } \\
\text { atualidade/regularidade; } \\
\text { sensibilidade; especificidade. }\end{array}$ & $\begin{array}{l}\text { Registros demográficos; } \\
\text { pesquisas geradas nos } \\
\text { procedimentos dos próprios } \\
\text { programas. }\end{array}$ \\
\hline $\begin{array}{l}\text { Avaliação } \\
\text { Indicadores que permitam } \\
\text { "revelar" a eficácia e } \\
\text { efetividade social dos } \\
\text { programas. }\end{array}$ & $\begin{array}{l}\text { Resultados e impactos; } \\
\text { distância das metas } \\
\text { (déficits sociais); tipologias } \\
\text { (boas práticas etc.). }\end{array}$ & $\begin{array}{l}\text { Pesquisas amostrais; registros } \\
\text { administrativos; grupos focais; } \\
\text { pesquisas de egressos de } \\
\text { participantes do programa. }\end{array}$ \\
\hline
\end{tabular}

Fonte: JANNUZZI, P. de M. Indicadores para diagnóstico, monitoramento e avaliação de programas sociais no Brasil. Revista do Serviço Público, Brasília, DF, v. 56, n. 2, p. 137-160, abr./jun. 2005. p. 48.

Segundo Lemos (2009), existe um consenso de que todo monitoramento e avaliação baseiam-se em indicadores que auxiliam nas tomadas de decisão, possibilitando um melhor desempenho, a formulação de um orçamento mais racional e uma prestação de contas mais clara e objetiva. De acordo com Minayo (2009, p. 84, grifo da autora): 


\begin{abstract}
A definição do termo "indicador", do ponto de vista científico, varia pouco de um autor para outro. Em geral, os pesquisadores consideram que os indicadores constituem parâmetros quantificados ou qualitativos que servem para detalhar se os objetivos de uma proposta estão sendo bem conduzidos (avaliação de processo) ou foram alcançados (avaliação de resultados). Como uma espécie de sinalizadores da realidade, a maioria dos indicadores dá ênfase ao sentido de medida e balizamento de processos de construção da realidade ou de elaboração de investigações avaliativas.
\end{abstract}

Um indicador social, ou melhor, um sistema de indicadores sociais, para uso no ciclo de políticas públicas, inicia-se a partir da explicitação da demanda de interesse programático (JANNUZZI, 2005), tais como a proposição de programas para ampliação de atendimento à saúde, de redução do déficit habitacional, de aprimoramento do desempenho escolar e de melhoria das condições de vida de comunidades. $\mathrm{O}$ autor afirma que os indicadores sociais são medidas usadas para permitir a operacionalização de um conceito abstrato ou de uma demanda de interesse determinado. Os indicadores apontam, indicam, aproximam, traduzem em termos operacionais as dimensões sociais de interesse, definidas a partir de escolhas teóricas ou políticas realizadas anteriormente.

Na relação entre processos e resultados, surge outra possibilidade para os estudos avaliativos: avaliação de eficácia, avaliação de eficiência e avaliação de efetividade. A distinção entre as três é basicamente um recurso analítico destinado a separar aspectos distintos dos objetivos e, por consequência, da abordagem e dos métodos e técnicas de avaliação. Jannuzzi (2005) situa os 3Es nas três fases de um processo avaliativo, o Quadro 2 sintetiza o entendimento do autor.

Minayo (2009, p. 85), em sentido similar, conceitua os 3Es da avaliação da seguinte forma:

Eficiência diz respeito à boa utilização de recursos financeiros, materiais e humanos em relação às atividades e resultados alcançados. Eficácia se refere à relação entre as ações realizadas e os resultados obtidos. Efetividade é a observação da incorporação das mudanças geradas por determinado programa na realidade da população-alvo. Impacto corresponde ao poder de influência e de irradiação de um projeto realizado.

Contudo, torna-se imprescindível a utilização harmoniosa de tais indicadores, o que pode ocorrer por meio da orientação de $\mathrm{Wu}$ 
AVALIACCÃO DO PROGRAMA UM MILHÃO DE CISTERNAS RURAIS (PIMC):

eficácia, eficiência e efetividade nos territórios do Rio Grande do Norte (2003-2015)

e outros (2014), que defendem que a avaliação contribui para o processo de criação de políticas públicas.

Quadro 2 - Os 3Es nas três fases da avaliação

\begin{tabular}{|c|c|c|c|}
\hline \multirow{2}{*}{ INDICADOR } & \multicolumn{3}{|c|}{ FASE } \\
\hline & Ex ante & Pari passu & Expost \\
\hline Eficiência & $\begin{array}{l}\text { Estimativas } \\
\text { baseadas } \\
\text { em iniciativas } \\
\text { comparáveis. } \\
\text { Pouco utilizada. }\end{array}$ & $\begin{array}{l}\text { Comparação entre o que } \\
\text { foi previsto e o que se } \\
\text { está realizando. Utilizada } \\
\text { principalmente no controle } \\
\text { orçamentário. }\end{array}$ & $\begin{array}{l}\text { Comparação com } \\
\text { iniciativas similares ou } \\
\text { com o planejamento. Mais } \\
\text { utilizada. }\end{array}$ \\
\hline Eficácia & $\begin{array}{l}\text { Baseada em } \\
\text { iniciativas } \\
\text { comparáveis. Pouco } \\
\text { utilizadas. }\end{array}$ & $\begin{array}{l}\text { Acompanhamento da } \\
\text { realização das } \\
\text { metas propostas. }\end{array}$ & $\begin{array}{l}\text { Verificação se as metas } \\
\text { propostas foram atingidas. }\end{array}$ \\
\hline Efetividade & $\begin{array}{l}\text { Expectativa } \\
\text { baseada em } \\
\text { iniciativas similares. } \\
\text { Pouco utilizada. }\end{array}$ & $\begin{array}{l}\text { Avaliações parciais ao } \\
\text { término das etapas de um } \\
\text { programa. }\end{array}$ & $\begin{array}{l}\text { Vinculação das mudanças, } \\
\text { caso tenham ocorrido as } \\
\text { ações empreendidas. Mais } \\
\text { utilizada e recomendada. }\end{array}$ \\
\hline
\end{tabular}

Fonte: SANO, H.; MONTENEGRO FILHO, M. J. F. As técnicas de avaliação da eficiência, eficácia e efetividade na gestão pública e sua relevância para o desenvolvimento social e das ações públicas. Desenvolvimento em Questão, ljuí, RS, v. 11, n. 22, p. 35-61, 2013. p. 41.

Silva (1999) utiliza outra definição, porém, com a mesma essência das fases citadas. Divide, assim, as avaliações com foco nos resultados em três tipos: (a) estudos de resultados antecipados, aqueles que os formuladores dos programas esperam atingir com sua implementação; (b) estudos de resultados não antecipados; e (c) análise de impacto, que permite entender se o programa realmente produz os benefícios que se espera para os beneficiários, e em que intervalo de tempo trata. Na análise de impactos, ou seja, de efeitos, os indicadores de eficiência, eficácia e efetividade são frequentemente utilizados a partir dos seguintes entendimentos: quanto à avaliação de eficiência, entende-se como a avaliação da relação entre o esforço empregado na implementação de uma dada política e os resultados alcançados.

Arretche (1999) entende que a avaliação da eficiência é possivelmente hoje a mais necessária e a mais urgente, e, na verdade, tem ocorrido sofisticação nos métodos de avaliação de eficiência nos anos recentes. Para Howlett, Ramesh e Perl (2013), a avaliação tenta determinar os custos de um programa e traçar um julgamento, e, se 
esse montante de custo proporciona resultados com qualidade, esperados e eficientes. Por essa razão, a avaliação de eficiência, segundo Draibe (2001), investiga a relação entre o esforço empregado na implementação do programa (pensado enquanto custo) e os resultados alcançados (no sentido amplo da palavra). O questionamento típico para esse tipo de avaliação é se as atividades ou processos se organizam tecnicamente, da maneira mais apropriada; se operam com os menores custos para a produção máxima dos resultados esperados e no menor tempo possível.

Já na avaliação de eficácia, conhecida igualmente como adequação da avaliação de desempenho, examinam-se os processos e sistemas de implementação, com vistas a identificar os fatores facilitadores de resultados em quantidades e qualidades máximas e em períodos mais curtos; buscam-se, também, os obstáculos ao alcance desses resultados, assim, o desempenho de um dado programa é confrontado com suas metas e objetivos. Secchi (2014) concorda com a definição citada e diz que a avaliação de eficácia corresponde ao nível de alcance de metas ou objetivos preestabelecidos. Contudo, nesse tipo de avaliação, o desempenho de um dado programa é confrontado com os objetivos delineados, a fim de determinar se está atingindo os objetivos traçados no seu escopo, e se precisam ser ajustados à luz das conquistas do programa. (HOWLETT; RAMESH; PERL, 2013).

Por avaliação de efetividade entende-se o exame da relação entre a implementação de um determinado programa e seus impactos e/ou resultados. Segundo Costa e Castanhar (2003), esse tipo de avaliação, também chamada de impacto, objetiva indicar se o projeto tem efeitos (positivos) no ambiente externo em que interveio, em termos técnicos, econômicos, socioculturais, institucionais e ambientais. Draibe (2001) afirma que a avaliação da efetividade refere-se à relação entre objetivos e metas e impactos e efeitos, e que a efetividade de um programa mensura-se pelas quantidades e níveis de qualidade com que se realizam as alterações (impactos e efeitos) que se pretende provocar na realidade sobre a qual o programa incide.

\section{PROCEDIMENTOS METODOLÓGICOS}

A natureza da pesquisa é descritiva, o que, segundo Gil (2010), tem como objetivo a descrição das características de determinada população, salientando-se aquelas que têm por objetivo estu- 
AVALIACCÃO DO PROGRAMA UM MILHÃO DE CISTERNAS RURAIS (PIMC):

eficácia, eficiência e efetividade nos territórios do Rio Grande do Norte (2003-2015)

dar as características de um grupo. Adotou-se o estudo de caso, que, segundo Martins e Theóphilo (2009, p. 62), é "[...] uma investigação empírica que pesquisa fenômenos dentro de seu contexto real, buscando apreender a totalidade de uma situação, descrever, compreender e interpretar a complexidade de um caso concreto."

Foram utilizados dados primários, coletados mediante entrevista, e, dados secundários, como o Censo 2010 do Instituto Brasileiro de Geografia e Estatística (IBGE), relação de cisternas construídas no Rio Grande do Norte, fornecida pela ASA, por meio do Sistema de Informação de Gestão e Auditoria (SIGA NET) e relação dos territórios do estado do Rio Grande do Norte, divulgada no Diário Oficial dos Municípios do Estado do Rio Grande do Norte, em julho de 2015. O universo da pesquisa compreende todos os 10 territórios do estado do Rio Grande do Norte, que totalizam $167 \mathrm{mu}-$ nicípios.

No tocante à abordagem, há duas etapas - quantitativa e qualitativa - o que caracteriza pesquisa de métodos mistos. Yin (2010) define que a pesquisa de métodos mistos pode permitir que os pesquisadores abordem questões de pesquisa complexas e coletem uma série mais rica e mais forte de evidências do que poderiam obter por qualquer método isoladamente. Nesse sentido, Creswell (2010) relata que diferentes perspectivas metodológicas complementam-se para análise de um tema, sendo esse processo compreendido como complementar das deficiências e dos pontos obscuros de cada método isolado.

A primeira etapa é quantitativa, e objetivou identificar os territórios mais eficientes do estado, aplicando-se, para tanto, a Análise Envoltória de Dados (Data Envelopment Analysis - DEA). Jannuzzi (2005) defende que a DEA é uma técnica derivada dos métodos de pesquisa operacionais que visam à identificação das unidades de operação mais eficientes, tendo em vista como os recursos são utilizados para gerar os resultados finais, considerando as condições estruturais de operação dos programas. Giacomello e Oliveira (2014) afirmam que DEA é a técnica que se baseia no pressuposto de que se uma unidade tomadora de decisão (Decision-Making Units - DMUs) é capaz de produzir uma determinada saída Y (output) utilizando $\mathrm{X}$ entradas (inputs), então outras DMUs também poderiam fazer o mesmo, caso estivessem atuando eficientemente. Assim, a população rural dos municípios torna-se inputs, e, o número de cisternas 
construído, outputs. A DEA fornece indicador de eficiência entre $0 \mathrm{e}$ 1, ou seja, de $0 \%$ a $100 \%$, de modo que índices com eficiência 1 são considerados efetivamente eficientes.

A DEA, resumidamente, busca identificar os melhores desempenhos em nível de operação, dessa forma, cada produto será comparado com os melhores desempenhos observados. No momento da estruturação de um modelo DEA, são de fundamental importância as seguintes definições: quais as unidades a serem avaliadas; quais as variáveis, insumos (inputs) e produtos (output) de avaliação; e qual o modelo DEA utilizado (CCR ou BCC - orientação a insumo ou orientação a produto). Para esta pesquisa, adotou-se o modelo BCC (orientação a produto), por considerar que um aumento nos inputs poderá promover um aumento nos outputs, não necessariamente na mesma proporção, diferindo do modelo CCR que opera com retornos constantes de escala. Como atividade de monitoramento ou de avaliação, é importante analisar os indicadores de resultados a partir dos indicadores de esforços e recursos alocados, o que permite o dimensionamento da eficiência dos programas. O emprego da DEA pode representar grande avanço metodológico nesse sentido. (LINS; MEZA, 2000). Os resultados colhidos do modelo DEA foram obtidos com a utilização do software Sistema Integrado de Apoio à Decisão (SIAD).

Não integraram a totalização da população rural do território os seguintes municípios adiante indicados, por parênteses, que não foram contempladas pelo programa, a respectiva população rural excluída para efeito da análise da eficiência: Arés (4851), Baía Formosa (1441), Canguaretama (10690), Montanhas (2543), Pedro Velho (6867), Senador Georgino Avelino (43), Tibal do Sul (45320), Nísia Floresta (14438), São José de Mipibu (21541), Goianinha (6998), do território do Agreste Litoral Sul; Serrinha dos Pintos (2136) e Viçosa (77), do território do Alto Oeste; Maxaranguape (6553) e Rio do Fogo (6313), do território do Mato Grande; Natal (0), Parnamirim (0), São Gonçalo (13564) e Extremoz (8770), do território Terra Potiguaras. Sendo assim, o universo passou a 149 municípios. A Tabela 1 apresenta os territórios do Rio Grande por número de municípios, população rural e número de cisternas instaladas. 
AVALIACCÃO DO PROGRAMA UM MILHÃO DE CISTERNAS RURAIS (PIMC): eficácia, eficiência e efetividade nos territórios do Rio Grande do Norte (2003-2015)

Tabela 1 - Representação do universo da pesquisa

\begin{tabular}{lccc}
\hline \multicolumn{1}{c}{ Território } & $\mathrm{N}^{0}$ de municípios & População rural & $\mathrm{N}^{0}$ de cisternas \\
\hline Açu-Mossoró & 14 & 87.030 & 10.743 \\
Agreste Litoral Sul & 11 & 49.343 & 3.001 \\
Alto Oeste & 28 & 66.902 & 8.202 \\
Mato Grande & 14 & 103.554 & 9.064 \\
Potengi & 11 & 37.895 & 4.354 \\
Seridó & 25 & 70.676 & 5.425 \\
Sertão Central & 10 & 30.660 & 3.514 \\
Sertão do Apodi & 17 & 55.790 & 11.521 \\
Terra Potiguaras & 1 & 26.852 & 1.655 \\
Trairí & 18 & 59.174 & 6.341 \\
\hline
\end{tabular}

Fonte: Elaborada pelos autores (2016).

Na segunda etapa (qualitativa) consideraram-se para esta pesquisa os territórios com resultados acima da média em eficiência. $\mathrm{O}$ instrumento de coleta de dados adotado foi a entrevista estruturada, que apresenta, segundo Gil (2010), a formulação de uma relação fixa de perguntas, cuja ordem e redação permanecem invariáveis para todos os entrevistados. A seleção dos entrevistados ocorreu por meio da amostragem teórica, uma vez que não utiliza técnicas estatísticas para tal determinação e não delimita de maneira rígida o tamanho. (FLICK, 2009). Para isso, foi utilizada a técnica amostragem em bola de neve. A escolha dos entrevistados nos três territórios mais eficientes do Rio Grande do Norte recaiu em representantes dos três segmentos - executor, mobilizador e beneficiário - identificados com o P1MC com reconhecido domínio acerca do tema abordado.

Superada a etapa de sistematização dos dados, o processamento e a análise foram realizados por meio do software NVivo11, resultando na exibição da nuvem de palavras que tem como finalidade agrupar e organizar graficamente em função de frequências.

Com o propósito de preservar a identidade, os participantes desta fase qualitativa da pesquisa, cuja coleta de dados ocorreu por meio de entrevista com um representante de cada segmento - Executor, mobilizador e beneficiário. Estão assim nominados na análise que se segue, procedida mediante suporte do software NVivo11:

E1_SA: Executor do Território do Sertão do Apodi

M1_SA: Mobilizador do Território do Sertão do Apodi

B1_SA: Beneficiário do Território do Sertão do Apodi

E2_MG: Executor do Território do Mato Grande 
M2 MG: Mobilizador do Território do Mato Grande

B2_ MG: Beneficiário do Território do Mato Grande

E3_AM: Executor do Território Açu-Mossoró

M3_AM: Mobilizador do Território Açu-Mossoró

B3_AM: Beneficiário do Território Açu-Mossoró

\section{ANÁLISE E DISCUSSÕES}

Esta seção trata da análise dos dados por meio dos indicadores: (a) eficácia, relacionada ao cumprimento da meta de instalação de 1 milhão de cisternas; (b) eficiência, no tocante ao desempenho do P1MC nos territórios, apurado por meio da relação população rural e número de cisternas instaladas; (c) efetividade, avaliada qualitativamente a partir de efeitos do P1MC relatados por interessados e sistematizados com base no conteúdo de três pressupostos do Programa. A descrição de tais indicadores segue, no presente capítulo, esta ordem - eficácia, eficiência, efetividade.

No que se refere à eficácia, é pertinente registrar, inicialmente, que o P1MC assume o propósito de beneficiar famílias de pequenos agricultores, propiciando não apenas acesso à agua, mas, também, uma nova visão do semiárido por meio do convívio harmônico com as adversidades da região. O P1MC definiu, como meta de partida, a construção, entre 2003 e 2008, de um milhão de cisternas no conjunto dos estados da Federação contemplados. A Tabela 2 ilustra as metas por estado, previstas para suprir demandas no semiárido brasileiro (conforme delimitado no mapa da Figura 11) geograficamente localizado nas regiões Nordeste (excetuado o estado do Maranhão) e Sudeste (Minas Gerais e Espírito Santo). As metas estão distribuídas por ano, ao longo dos cinco anos originalmente previstos.

Tabela 2 - Meta e cronograma da implementação de cisternas

\begin{tabular}{cccrrrrrrrrrr}
\hline Ano & Total de cistemas & NN UGS $^{\circ}$ & AL & BA & CE & ES & MG & PB & PE & PI & RN & SE \\
\hline $1^{0}$ & 45.000 & 47 & 1.100 & 9.500 & 6.600 & 600 & 1.200 & 7.800 & 6.700 & 4.000 & 6.400 & 1.100 \\
$2^{\circ}$ & 138.500 & 54 & 6.000 & 30.000 & 18.000 & 1.500 & 3.000 & 24.000 & 24.000 & 10.000 & 16.000 & 6.000 \\
$3^{\circ}$ & 275.400 & 64 & 9.700 & 83.800 & 53.000 & 1.500 & 6.000 & 38.700 & 38.700 & 15.000 & 24.000 & 5.000 \\
$4^{\circ}$ & 299.100 & 64 & 9.700 & 109.200 & 53.000 & 2.000 & 6.700 & 39.700 & 39.700 & 19.000 & 15.400 & 4.700 \\
$5^{\circ}$ & 242.000 & 64 & 13.400 & 104.500 & 44.400 & 2.000 & 5.300 & 4.800 & 36.900 & 14.000 & 12.000 & 4.700 \\
\hline Total & 1.000 .000 & 293 & 39.900 & 337.000 & 175.000 & 7.600 & 22.200 & 115.000 & 146.000 & 62.000 & 73.800 & 21.500 \\
\hline
\end{tabular}

Fonte: SANTOS, M. J. dos et al. Programa um Milhão de Cisternas Rurais: matriz conceitual e tecnológica. UNOPAR Científica Ciências Exatas e Tecnológicas, Londrina, v. 8, n. 1, p. 35-43, nov. 2009.

Nota: UGs $=$ unidades gestoras. 
AVALIACCÃO DO PROGRAMA UM MILHÃO DE CISTERNAS RURAIS (PIMC):

eficácia, eficiência e efetividade nos territórios do Rio Grande do Norte (2003-2015)

A meta física total almejada pelo Programa compreendia, conforme ilustra a Tabela 2, a instalação de um milhão de cisternas ao longo de 5 anos. Do total de um milhão de cisternas, até setembro de 2015 , quando se encerrou a coleta desta pesquisa, havia sido construído o total de 578.447 cisternas, representando $57,84 \%$ da meta original e garantindo o acúmulo de até 9.255.152.000 litros de água potável. Desse modo, a meta até 2008 não foi alcançada e, em setembro de 2015 , menos de $2 / 3$ das cisternas encontravam-se construídas. No Rio Grande do Norte, o atingimento da meta física é superior à média do conjunto, e, até o encerramento da coleta desta pesquisa, havia registro de construção de 63.820 cisternas, representando 87\% da meta para o estado.

A eficiência, como dito anteriormente, utilizou a DEA, que é um modelo matemático (programação linear) não paramétrico, capaz de avaliar desempenho organizacional em termos da relação entre unidades similares, chamadas de unidades tomadoras de decisão, que apresentam múltiplas entradas e múltiplas saídas. (RAMOS, 2010).

Tabela 3 - Eficiência dos territórios do Rio Grande do Norte

\begin{tabular}{|c|c|c|c|c|c|c|c|}
\hline $\begin{array}{c}\text { DMUs } \\
\text { territórios }\end{array}$ & $\begin{array}{c}\text { Municípios } \\
\text { contemplados }\end{array}$ & $\begin{array}{l}\text { Input } \\
\text { População } \\
\text { rural }\end{array}$ & $\%$ & $\begin{array}{c}\text { Output } \\
\text { Cisternas } \\
\text { construídas }\end{array}$ & $\%$ & $\begin{array}{l}\text { Eficiência } \\
\text { DEA/BCC }\end{array}$ & $\begin{array}{l}\text { Ordem } \\
\text { eficiência }\end{array}$ \\
\hline $\begin{array}{l}\text { Sertão do } \\
\text { Apodi }\end{array}$ & 17 & 55.790 & 9,5 & 11.521 & 18,1 & 1 & $1^{\circ}$ \\
\hline $\begin{array}{l}\text { Terras } \\
\text { Potiguaras }\end{array}$ & 1 & 26.852 & 4,6 & 1.655 & 2,6 & 1 & $2^{\circ}$ \\
\hline $\begin{array}{l}\text { Açu- } \\
\text { Mossoró }\end{array}$ & 14 & 87.030 & 14,8 & 10.743 & 16,8 & 0,96 & $3^{\circ}$ \\
\hline $\begin{array}{l}\text { Mato } \\
\text { Grande }\end{array}$ & 14 & 103.554 & 17,6 & 9.064 & 14,2 & 0,76 & $4^{\circ}$ \\
\hline Alto Oeste & 28 & 66.902 & 11,4 & 8.202 & 12,9 & 0,59 & $5^{\circ}$ \\
\hline Potengi & 11 & 37.895 & 6,4 & 4.354 & 6,8 & 0,58 & $6^{\circ}$ \\
\hline $\begin{array}{l}\text { Sertão C.L. } \\
\text { Norte }\end{array}$ & 10 & 30.660 & 5,2 & 3.514 & 5,5 & 0,55 & $7^{\circ}$ \\
\hline Trairí & 18 & 59.174 & 10,1 & 6.341 & 9,9 & 0,52 & $8^{\circ}$ \\
\hline Seridó & 25 & 70.676 & 12,0 & 5.425 & 8,5 & 0,37 & $9^{\circ}$ \\
\hline $\begin{array}{l}\text { Agreste } \\
\text { Litoral Sul }\end{array}$ & 11 & 49.343 & 8,4 & 3.001 & 4,7 & 0,35 & $10^{\circ}$ \\
\hline Totais & 149 & 587.876 & 100 & 63.820 & 100 & & \\
\hline \multicolumn{5}{|c|}{ Média da eficiência obtida } & & 0,67 & \\
\hline
\end{tabular}

Fonte: Elaborada pelos autores (2016). 
A Tabela 3 apresenta as DMUs identificadas por território do Rio Grande do Norte. Foi utilizada, como variável de entrada (input), a população rural, considerando ser este o público-alvo da ação, ao passo que o quantitativo de cisternas construídas assumiu a condição de variável de saída (output). Destaca-se a não utilização de outros inputs como: recursos humanos e, custos do projeto, devido aos mesmos serem muito semelhantes em todas as DMU's, visto que para execução do Programa, essas variáveis são pré-definidas, o que apresentaria uma variação baixa e irrelevante no cálculo da eficiência. Os territórios que apresentam maior eficiência, ou eficiência máxima, foram Sertão do Apodi e Terras Potiguaras com resultado igual a 1,0, significando que, em ambos, as demandas foram atendidas em níveis mais elevados e satisfatórios quando comparados aos demais. Nesse sentido, Sertão do Apodi e Terras Potiguares alcançam o coeficiente máximo no conjunto dos dez territórios, quando comparados ao desempenho dos demais. É relevante registrar que, no Território Terras Potiguaras, apenas um dos cinco municípios foi contemplado com cisterna (Macaíba) e, além disso, o Território/município não está localizado no semiárido, considerando sua posição geográfica em parte do litoral leste do estado, na Grande Natal.

Os territórios Açu-Mossoró, com 0,96, e Mato Grande, com 0,76 , apresentam resultados igualmente elevados em termos de eficiência, com desempenhos acima da média de 0,67 obtida pelo conjunto. Nesse quesito, é pertinente destacar que o Território Sertão do Apodi (11.521) alcança desempenho mais expressivo, pois, detendo população rural que corresponde a $54 \%$ da população rural do Mato Grande (9.064), implantou 2.457 cisternas a mais, representando $21,3 \%$ de diferença. Outro dado importante nesse resultado é que os territórios Seridó (5.425) com 0,37 e Sertão Central (3.514) com 0,55 apresentam historicamente os mais baixos índices pluviométricos do Rio Grande do Norte, no entanto, a eficiência encontrada é inversamente proporcional a essa realidade. Pode ter ocorrido que, especialmente no caso do Seridó, outras alternativas de acesso à água tenham sido implantadas considerando o histórico daquele território que apresenta outros indicadores socioeconômicos relativamente elevados no Estado (Tabela 4). 
AVALIACCÃO DO PROGRAMA UM MILHÃO DE CISTERNAS RURAIS (PIMC):

eficácia, eficiência e efetividade nos territórios do Rio Grande do Norte (2003-2015)

Tabela 4 - Classificação dos territórios por intervalo de eficiência

\begin{tabular}{lcc}
\hline Classificação & Quantidade & Territórios do Rio Grande do Norte \\
\hline Acima da média & 4 & $\begin{array}{c}\text { Açu-Mossoró, Mato Grande } \\
\text { Sertão do Apodi, Terras Potiguaras }\end{array}$ \\
\hline Média & 0,67 \\
\hline Abaixo da média & 6 & $\begin{array}{c}\text { Seridó, Agreste Litoral Sul } \\
\text { Sertão Central, Alto Oeste, Trairí, Potengi }\end{array}$ \\
\hline
\end{tabular}

Fonte: Elaborada pelos autores (2016).

Frente a esse desempenho, para efeitos de avaliação da efetividade do P1MC, realizada na sequência, o território Terras Potiguaras foi desconsiderado, por possuir apenas um município contemplado com cisternas, apresentar a menor população rural territorial, com apenas 4,6\% do total do estado, e, além disso, não integrar o semiárido potiguar.

A fase de análise da efetividade - realizada qualitativamente por meio de entrevista a representantes dos segmentos executores, mobilizador de campo e beneficiário - ganha maior relevância. No que se refere ao pressuposto, Fortalecimento da autoestima, as respostas dos informantes nos três territórios convergem para entendimentos comuns, entre os envolvidos, em torno do tema. Em várias falas fica evidenciada a transformação no interior da família após receber a cisterna.

O mobilizador M3_AM descreve a satisfação das famílias nesse quesito, enaltecendo a chegada do reservatório que antes não existia. “[...] não tínhamos um reservatório para colocar água, e hoje você chega em todas as comunidades e vê as cisternas cheinhas, pintadinhas, e a maior parte delas com água, e graças a Deus as famílias contentes." (Informação verbal). ${ }^{1}$

B1_SA potencializa os argumentos acima depositando na cisterna valor tão elevado quanto a própria água, justificando que a existência do reservatório facilita o acesso: "[...] eu, como agricultor, em 2011 recebi minha cisterna e foi uma mudança e tanto, porque você não tem onde colocar água, né? Muita gente fala assim: cisterna não é água; sim, a cisterna não é agua, mas, se você tem a cisterna, você tem facilidade de arrumar água." (Informação verbal). ${ }^{2}$ 
A água adquirida por meio de cisternas, não apenas torna mais seguro o acesso e a preservação da qualidade, mas, também, permite a guarda em volumes maiores.

Figura 1 - Nuvem de palavras do pressuposto Fortalecimento da Autoestima

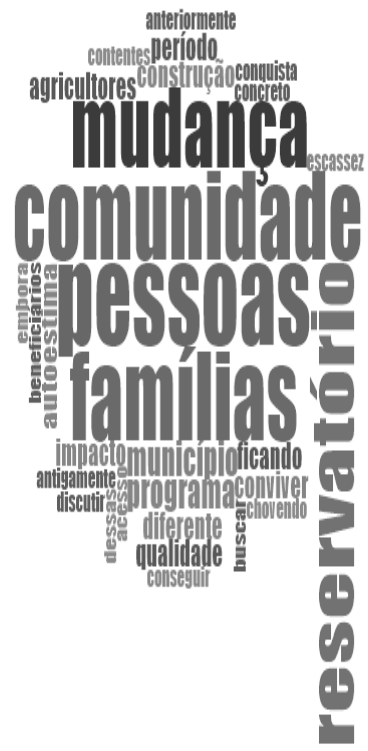

Fonte: Elaborada pelos autores (2016).

O pressuposto Fortalecimento da cidadania foi abordado com base na seguinte questão: após a implementação das cisternas, ocorreu alguma mudança na comunidade? De modo geral, pode-se observar que as mudanças não dizem respeito somente à disponibilidade de reservatório e água potável na casa do beneficiário (Figura 1).

M2_MG aborda, por outro caminho, esse fenômeno, quando destaca a autonomia e o direito à água rompendo com a indústria da seca e a tradição de relações clientelistas, frequentemente manifestas por meio da barganha política:

Acho que a principal mudança é a autonomia das famílias, que a gente sabe da indústria da seca que sempre prevaleceu aqui na região [Nordeste] e, agora, a gente percebe que as famílias ficam mais autônomas, não ficam tão dependentes do poder público e a água que era tida como um favor, passa a ser um direito. É essa 
AVALIAÇÃO DO PROGRAMA UM MILHÃO DE CISTERNAS RURAIS (P1MC):

eficácia, eficiência e efetividade nos territórios do Rio Grande do Norte (2003-2015)

conscientização mesmo das pessoas: a água é um direito. (Informação verbal). ${ }^{3}$

Um beneficiário enfatiza que o P1MC "[...] é um desenvolvimento muito importante para as comunidades, pela participação, pelo trabalho; então, eu acho isso muito interessante." (Informação verbal) ${ }^{4}$. Dessa forma, comunidade, pessoas e famílias aparecem, mais uma vez, com destaque na nuvem de palavras (Figura 2).

Figura 2 - Nuvem de palavras - Fortalecimento da cidadania

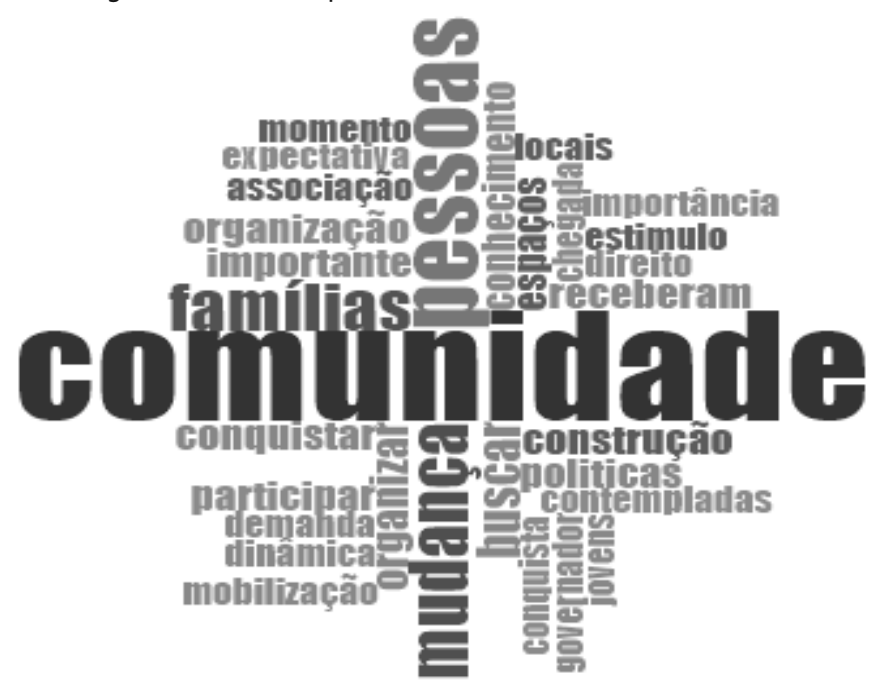

Fonte: Elaborada pelos autores (2016).

Na visão dos executores, a maior aprendizagem está na formação de uma consciência política entre as famílias, contextualizada, própria ao semiárido, e no despertar da noção de conquista e descoberta de capacidades entre os beneficiários: Os beneficiários, por sua vez, julgam, como aprendizagem, na jornada proporcionada pelo Programa, o zelo pela cisterna, o cuidado para preservar a qualidade da água e a tomada de consciência em torno da realidade no conjunto do semiárido:

Eu aprendi muita coisa. Primeiro a gente aprendeu como é cuidar da cisterna. A gente aprendeu como é que cuida da água e a gente aprendeu porque a gente vê nas outras comunidades as dificuldades, a gente vê a realidade do mundo lá fora como é também e a 
gente acha que só quem tem dificuldades somos nós, né? Mas aí a gente sai e vê a realidade e muita gente ainda batalhando por essa cisterna para cada vez melhorar mais. (Informação verbal) ${ }^{5}$.

A aprendizagem ocorreu, também, em torno da consciência para uso racional da água seguindo o restrito propósito do Programa, ou seja, em "[...] como utilizar a água, porque lá tem muitas pessoas que utilizam pra tudo no mundo, e é bom a gente usar só para o consumo humano." (Informação verbal).

Conforme se percebe, M1_SA enaltece um despertar, uma tomada de consciência quando o agricultor se vê diante de possibilidades de acesso a outras políticas públicas, e, corroborando esse entendimento, o executor E1_SA afirma que uma conquista está exatamente em:

Adquirir consciência política, porque já vi depoimentos em que políticos tentaram dizer que trouxeram as cisternas e o agricultor dizer que não foi. É claro que essa consciência não é para todo mundo, porque cada um tem um aprendizado diferente. Mas, eu acho que para grande maioria esse é o principal aprendizado. (Informação verbal). ${ }^{7}$

Outro executor, E2 MG, defende ponto de vista similar, reafirmando que o maior legádo é o fato de os beneficiários conseguirem usufruir de direitos o que, para ele, é conquista, um verdadeiro aprendizado:

O programa cria pra eles a capacidade que eles têm de conseguir as coisas. Você chega dando, inclusive sou contra esse tipo de coisa, mas, é um casamento de duas partes. O maior aprendizado é o despertar nas pessoas da capacidade de conquista. Desde as primeiras falas, falamos que elas são capazes. ${ }^{8}$

Além de falar em conquistas, E2 MG relata que outro ponto importante é o aprender a falar em público. Elas dizem: "Nunca pensei um dia falar para esse pessoal todo aqui reunido." (Informação verbal) ${ }^{9}$. Tal entendimento aponta para diferentes perspectivas de desenvolvimento humano trazidas pelo P1MC. Por essa razão, a nuvem de palavras, gerada pelo NVivo para o pressuposto Aprender fazendo, traz, ao lado de outras surgidas anteriormente, expressões como aprendizado, conhecimento, capacidade e realidade, esta denotando tomada de consciência em torno de políticas (outra agora surgida) voltadas às pessoas, ao agricultor, à comunidade (Figura 3 ). 
AVALIAÇÃO DO PROGRAMA UM MILHÃO DE CISTERNAS RURAIS (PIMC): eficácia, eficiência e efetividade nos territórios do Rio Grande do Norte (2003-2015)

Figura 3 - Nuvem de palavras - Aprender-fazendo

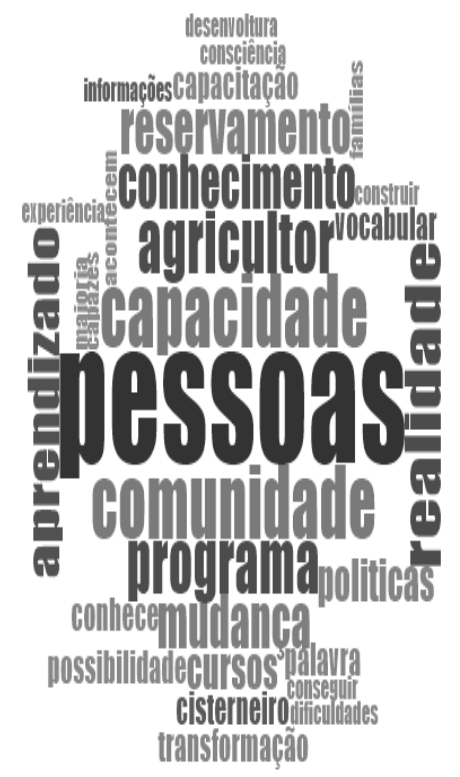

Fonte: Elaborada pelos autores (2016).

$\mathrm{Na}$ conexão estabelecida para os pressupostos pela ASA, Aprender-fazendo, no P1MC, requer Envolvimento das famílias, considerando a forte conotação coletivista inerente à ação, conforme ficou demonstrado no primeiro pressuposto aqui analisado e sintetizado como Fortalecimento da autoestima.

\section{CONCLUSÕES}

Esta pesquisa teve como objetivo analisar o P1MC em termos de eficácia, eficiência e efetividade no Rio Grande do Norte. No indicador eficácia, foi verificado atraso no cumprimento das metas físicas. Deveria se construir 1 milhão de cisternas em 5 anos, entre 2003 (a partir do mês de julho) e 2008. Todavia, até setembro de 2015 existiam 578.447 cisternas instaladas, representando 57,84\% da meta original, com percentual alcançado em período de tempo bem superior aos 5 anos. No Rio Grande do Norte, há registro de 63.820 cisternas construídas, o que significa $87 \%$ da meta proposta 
para o estado (de 73.000 até 2008) e desempenho superior à média alcançada pelo Programa no conjunto dos estados contemplados.

Diante desses números, o governo federal adotou uma medida paralela ao P1MC, que consistia na instalação de cisternas de plástico sem adoção dos pressupostos estabelecidos pelas organizações da sociedade civil aglutinadas em rede na ASA. A intervenção do Estado, todavia, não surtiu o efeito esperado frente à rejeição dos segmentos interessados, especialmente o da população beneficiária. O desempenho do P1MC pode ser explicado pelo conteúdo e pela metodologia assumidos, que ultrapassam os propósitos de construção de cisternas e disponibilização de água potável. Ao contrário, envolvem encontros de mobilização, socialização, capacitações, organização comunitária e envolvimento das famílias, representando, nesse quesito, um diferencial na extensão rural ao assumir o compromisso da convivência com o semiárido.

A eficiência foi apurada com base no desempenho do P1MC no Rio Grande do Norte, segmento por território, com base na DEA, tendo como variável de entrada (input) a população rural e o quantitativo de cisternas instaladas como variável de saída (output). Quatro territórios potiguares apresentam desempenho elevado, em nível superior à média do estado: Sertão do Apodi e Terras Potiguaras, com resultado igual a 1,0 (o nível máximo comparativamente ao conjunto), Açu-Mossoró com 0,96 e Mato Grande com 0,76. O Território Terras potiguares possui cinco municípios (dos 167 do estado) e um apenas contemplado com cisterna (Macaíba), fica localizado no litoral e é composto por municípios da Região Metropolitana de Natal. Com tais características, possui reduzida população rural (apenas $4,6 \%$ do total do estado). Dessa forma, o Território não possui valor significativo à análise do conjunto, permitindo entender que a média estadual de desempenho, de 0,67 , foi ultrapassada por três territórios - Apodi, Açu-Mossoró e Mato Grande. O Sertão do Apodi desponta com o melhor desempenho, pois, com população rural de 55.790 habitantes, inferior em mais de $50 \%$ a do Mato Grande (que ultrapassa 100 mil habitantes rurais), recebeu 2.457 cisternas a mais.

Para a avaliação do indicador efetividade, entrevistas foram realizadas com representantes dos três segmentos envolvidos - executor, mobilizador e beneficiário - nos três territórios em pauta, com elevado desempenho em eficiência - Sertão do Apodi, Açu-Mossoró e Mato Grande. Tal avaliação recorreu em termos qualitativos, dire- 
AVALIACCÃO DO PROGRAMA UM MILHÃO DE CISTERNAS RURAIS (PIMC):

eficácia, eficiência e efetividade nos territórios do Rio Grande do Norte (2003-2015)

cionada à compreensão do modo como o $\mathrm{P} 1 \mathrm{MC}$ atende aos pressupostos analisados, expressos pela ASA no documento de referência do Programa. Os efeitos são amplamente satisfatórios e, portanto, o P1MC cumpre com os pressupostos analisados - Fortalecimento da autoestima, Fortalecimento da cidadania, Aprender-fazendo. Conclui-se, assim, que o P1MC possui eficácia regular no cumprimento das metas gerais estabelecidas para o semiárido o mesmo ocorrendo em termos de eficiência, quando analisados os dez territórios do Rio Grande do Norte. Todavia, o Programa é amplamente efetivo no atendimento aos seus pressupostos, que possuem nítido caráter centrado na formação para a convivência com o semiárido, pelo viés da autonomia das famílias e da organização sociopolítica e da comunitária. A dedicação aos pressupostos políticos assumidos, com procedimentos metodológicos que envolvem mobilizações, organização comunitária, aprendizagens coletivas, estabelecimento de relações de confiança e mudanças duradouras nas comunidades e nas famílias para convivência com a seca, pode explicar entraves no alcance dos números pretendidos.

\section{REFERÊNCIAS}

ARRETCHE, M. T. da S. Tendências no estudo sobre avaliação. In: RICO, E. M. (Org.). Avaliação de políticas sociais: uma questão em debate. 2. ed. São Paulo: Cortez: Instituto de Estudos Especiais, 1999. p. 1-10.

Uma contribuição para fazermos avaliações menos ingênuas. In: BARREIRA, M. C. R. N.; CARVALHO, M. do C. B. de (Orgs.). Tendências e perspectivas na avaliação de políticas sociais. São Paulo: IEE/PUC-SP, 2001. p. 1-12.

ARTICULAÇÃO DO SEMIÁRIDO BRASILEIRO. Sobre nós: ações - P1MC. [S. 1.], [2016]. Disponível em: <http://www.asabrasil.org.br>. Acesso em: 29 maio 2016.

CAVALCANTI, M. M. de A. Avaliação de políticas públicas e programas governamentais: uma abordagem conceitual. Interfaces de Saberes, João Pessoa, v. 6, p. 1-13, 2006.

COSTA, F. L. da; CASTANHAR, J. C. Avaliação de programas públicos: desafios conceituais e metodológicos. RAP, Rio de Janeiro, v. 37, n. 5, p. 969-92, 2003. 
CRESWELL, J. W. Projeto de pesquisa: métodos qualitativo, quantitativo e misto. Tradução de Magda Lopes. 3. ed. Porto Alegre: Artmed, 2010.

DEMO, P. Pobreza política, a pobreza mais intensa da pobreza brasileira. Campinas, SP: Armazém do Ipê, 2006.

DRAIBE, S. M. Avaliação de implementação: esboço de uma metodologia de trabalho em políticas. In: BARREIRA, M. C. R. N.; CARVALHO, M. do C. B. de (Orgs.). Tendências e perspectivas na avaliação de políticas sociais. São Paulo: IEE/PUC-SP, 2001. p. 13-42.

FARIA, C. A. P. de. A política da avaliação de políticas públicas. Revista Brasileira de Ciências Sociais, São Paulo, v. 20, n. 59, p. $97-$ 106, 2005.

FIGUEIREDO, M. F.; FIGUEIREDO, A. M. C. Avaliação política e avaliação de políticas: um quadro de referência teórica. São Paulo: IDESP, 1986.

FLICK, U. Introdução à pesquisa qualitativa. 3. ed. Porto Alegre: Artmed, 2009.

FREY, K. Políticas públicas: um debate conceitual e reflexões referentes à prática da análise de políticas públicas no Brasil. Planejamento e Políticas Públicas, Brasília, DF, n. 21, p. 211-259, jun. 2001.

GIACOMELLO, C. P.; OLIVEIRA, R. L. de. Análise Envoltória de Dados (DEA): uma proposta para avaliação de desempenho de unidades acadêmicas deuma universidade. Revista Gestão Universitária na América Latina - GUAL, Santa Catarina, v. 7, n. 2, p. 130-151, maio 2014.

GIL, A. C. Como elaborar projetos de pesquisa. São Paulo: Atlas, 2010. v. 5.

HOWLETT, M.; RAMESH, M.; PEARL, A. Política pública: seus ciclos e subsistemas: uma abordagem integral. Rio de Janeiro: Elsevier, 2013.

JANNUZZI, P. de M. Indicadores para diagnóstico, monitoramento e avaliação de programas sociais no Brasil. Revista do Serviço Público, Brasília, DF, v. 56, n. 2, p. 137-160, abr./jun. 2005.

LEMOS, C. S. Gestão pública orientada para resultados: avaliando o caso de Minas Gerais. 2009. 116 f. Dissertação (Mestrado em Administração Pública) - Fundação Getúlio Vargas, Rio de Janeiro, 2009. 
AVALIACCÃO DO PROGRAMA UM MILHÃO DE CISTERNAS RURAIS (PIMC): eficácia, eficiência e efetividade nos territórios do Rio Grande do Norte (2003-2015)

LINS, M. P. E.; MEZA, L. Â. Análise envoltória de dados e perspectivas de integração no ambiente de apoio à decisão. Rio de Janeiro: COPPE/UFRJ, 2000.

LIRA, P. G. R. et al. P1MC e resiliência: um estudo no município de Soledade-PB. In: JORNADA INTERNACIONAL DE POLÍTICAS PÚBLICAS, 5., 2011, São Luís. Anais... São Luís: UFMA, 2011.

LOPES, E. S. A.; LIMA, S. L. S. Análise do programa um milhão de cisternas rurais-P1MC, no município de Tobias Barreto, estado de Sergipe. In: MELO, R. O. L. de; HANSEN, D. L. (Orgs.). Ensaios econômicos: conceitos e impasses do desenvolvimento regional. 1. ed. Aracaju: EDUFS, 2009. v. 1, p. 275-324.

MATIAS-PEREIRA, J. Curso de planejamento governamental: foco nas políticas públicas e nos indicadores sociais. São Paulo: Atlas, 2012 .

MARTINS, G. de A.; THEÓPHILO, C. R. Metodologia da investigação cientifica. São Paulo: Atlas, 2009.

MINAYO, M. C. de S. Construção de indicadores qualitativos para avaliação de mudanças. Revista Brasileira de Educação Médica, Rio de Janeirov. 33, n. 1, p. 83-91, 2009. Suplemento 1.

PASSADOR, C. S.; PASSADOR, J. L. Apontamentos sobre as políticas públicas de combate à seca no Brasil: cisternas e cidadania. Cadernos Gestão Pública e Cidadania, São Paulo, v. 15, n. 56, p. 65$86,2010$.

RAMOS, J. do A. Utilização da Análise Envoltória de Dados (DEA) como ferramenta de gestão de desempenho organizacional no setor público: uma avaliação da eficiência técnica do Instituto Federal da Bahia (IFBA). 2010. 57 f. Monografia (Especialização em Controladoria e Finanças) - Escola Superior Aberta do Brasil, Vila Velha, 2010.

SANO, H.; MONTENEGRO FILHO, M. J. F. As técnicas de avaliação da eficiência, eficácia e efetividade na gestão pública e sua relevância para o desenvolvimento social e das ações públicas. Desenvolvimento em Questão, Ijuí, RS, v. 11, n. 22, p. 35-61, 2013.

SANTOS, M. J. dos et al. Programa um Milhão de Cisternas Rurais: matriz conceitual e tecnológica. UNOPAR Científica Ciências Exatas e Tecnológicas, Londrina, v. 8, n. 1, p. 35-43, nov. 2009.

SECCHI, L. Políticas públicas: conceitos, esquemas de análise, casos práticos. 2. ed. São Paulo: Cengage Learning, 2014. 
SILVA, P. L. B. (Coord.). Modelo de avaliação de programas sociais prioritários: relatório final do Programa de Apoio à Gestão Social no Brasil: subcomponente desenho e implantação de estratégia de avaliação. Campinas, SP: NEPP/UNICAMP, 1999.

SMITH, T. B. The policy implementation process. Policy Sciences, [S. 1.], v. 4, n. 2, p. 197-209, 1973.

SOUZA, C. Políticas públicas: uma revisão da literatura. Sociologias, Porto Alegre, v. 8, n. 16, p. 20-45, 2006.

WU, X. et al. Guia de políticas públicas: gerenciando processos. Tradução de Ricardo Avelar de Souza. Brasília, DF: ENAP, 2014.

YIN, R. K. Estudo de caso: planejamento e métodos. 4. ed. Porto Alegre: Bookman, 2010.

\section{NOTAS}

Depoimento retirado da entrevista estruturada realizada na pesquisa.

2 Depoimento retirado da entrevista estruturada realizada na pesquisa.

3 Depoimento retirado da entrevista estruturada realizada na pesquisa com o M2_MG.

${ }^{4}$ Depoimento retirado da entrevista estruturada realizada na pesquisa com o B1_SA.

${ }^{5}$ Depoimento retirado da entrevista estruturada realizada na pesquisa com o B2_MG.

${ }^{6}$ Depoimento retirado da entrevista estruturada realizada na pesquisa com o B3_AM.

${ }^{7}$ Depoimento retirado da entrevista estruturada realizada na pesquisa.

${ }^{8}$ Depoimento retirado da entrevista estruturada realizada na pesquisa.

${ }^{9}$ Depoimento retirado da entrevista estruturada realizada na pesquisa. 